\title{
Role of fat-storing cells in schistosomal hepatic fibrosis of mice
}

\author{
Aryon de Almeida Barbosa $\mathrm{Jr}^{1}$, Ulrich Pfeifer ${ }^{2}$, and Zilton A. Andrade ${ }^{1}$ \\ ${ }^{1}$ Centro de Pesquisas Goncalo Moniz / Fiocruz, Salvador, Brazil \\ ${ }^{2}$ Department of Pathology, University of Bonn, Postfach 21 20, W-5300 Bonn 1, Germany
}

Received January 6/ Accepted February 26, 1993

Summary. The involvement of fat-storing cells (FSC) in hepatic schistosomal granuloma was investigated in mice infected with Schistosoma mansoni cercariae. After infection, 24 animals were treated with s.c. injections of vitamin $A$ in a total dose of 210,000 IU given twice a week for 3 weeks. Two other groups of 24 animals each were: a) non-infected vitamin A-treated animals and (b) untreated infected controls. Animals from all groups were killed at weekly intervals from the 5th through the 10 th week following infection. Pieces of liver were examined by light microscopy and transmission electron microscopy. In all vitamin A-treated animals, FSC disclosed prominent cytoplasmic fat droplets, which permitted their prompt identification in the light and in the electron microscope. They were found in large numbers as a constituent of periovular granulomas. In infected controls, FSC were not identified in granulomas, possibly because lipid droplets disappeared during differentiation to the fibroblastic phenotype. FSC also appeared within areas of septal fibrosis. These data suggest that FSC play an important part in focal portohepatic fibrosis during granuloma formation around $S$. mansoni eggs in the liver of mice.

Key words: Fat-storing cells - Schistosoma mansoni Liver fibrosis - Hypervitaminosis A - Schistosomal granulomas

\section{Introduction}

Fat-storing cells (FSC) are a major factor in hepatic fibrogenesis (Stenger 1966; McGee and Patrick 1972; Senoo et al. 1984; Gressner and Bachem 1990). They are fibroblast-like cells present in the Disse's perisinusoidal spaces and their main normal function seems to be

Correspondence to: U. Pfeifer, Pathologisches Institut der Universität the storage of retinols (vitamin A) within lipid droplets, which are characteristically present in the cytoplasm.

During activation FSC lose the fat droplets and differentiate into myofibroblasts and fibroblasts, and actively synthesize several components of the interstitial matrix, such as type I, III and IV collagens and laminin (Friedman et al. 1985; Maher et al. 1988), proteoglycans (Schafer et al. 1987), fibronectin (Ramadori et al. 1987), and hyaluronic acid (Gressner and Haarmann 1988).

FSC are prominent during the healing process in diffuse hepatic fibrosis with or without previous liver cell necrosis (Senoo and Wake 1985), in focal intraparenchymal hepatic injury (Ogawa et al. 1985) and in intraparenchymal granulomas (Dijkhuis et al. 1989). However, the involvement of FSC has not yet been investigated in granuloma formed within the portal tissue. The present study investigated the role of FSC in schistosomal granuloma fibrosis in the liver during experimental infection of mice and exploits the fact that treatment with excess vitamin A induces FSC to store large amounts of fat in cytoplasmic droplets for a time, thus facilitating their identification during histopathological studies.

\section{Materials and methods}

Eight-week-old outbred male Swiss mice were infected by the transcutaneous route with 30 recently shed Schistosoma mansoni cercariae. Starting 2 weeks after infection 24 animals received s.c. injections of 35,000 IU of retinyl palmitate (vitamin A, Arovit, Roche) twice a week, in a total dose of 210,000 IU. A second group of mice was similarly treated with vitamin A but not infected with S. mansoni. A third and last group was infected only with $30 \mathrm{~S}$. mansoni cercariae and not treated. The animals had access to a balanced commercial diet and water ad libitum.

Animals from all groups were killed by cervical dislocation at weekly intervals from the 5 th through the 10 th week following infection. All animals exposed to cercariae became infected and presented viable parasite eggs in the stools.

For light microscopy, sections were cut from paraffin embedded liver tissue. They were stained with hematoxylin $\&$ eosin, and Sirius red F3BA for collagen (picrosirius red method). For transmission electron microscopy, small cubes of liver (about $1 \mathrm{cmm}$ ) were immediately fixed by immersion with $2 \%$ glutaraldehyde in $0.075 \mathrm{M}$ caco- 


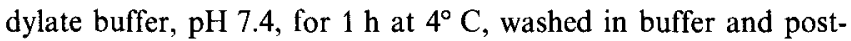
fixed with $1 \%$ osmium tetroxide, dehydrated in graded concentrations of ethanol and embedded in Epon 812 (Serva Feinbiochemica, Heidelberg, Germany). Sections of $1 \mu \mathrm{m}$ thickness were cut from these epon blocks, stained with toluidine blue, and were viewed with the light microscope for the appropriate areas, e.g. granulomas. Ultrathin sections $(50-70 \mathrm{~nm})$ were mounted on uncoated copper grids, stained with uranyl acetate and a mixture of lead citrate, acetate and nitrate. Specimens were examined in a Siemens Elmiskop 101 electron microscope, which was operated at an acceleration voltage of $80 \mathrm{kV}$.

\section{Results}

Eight animals infected with $S$. mansoni and treated with vitamin A died at completion of treatment. No mortality occurred in non-infected vitamin A-treated animals, or in mice infected with $S$. mansoni alone, although the latter presented a worm burden similar to that of the infected-treated group.

\section{Infected, non-treated animals}

In the infected and non-treated animals, hepatic granulomas appeared in different evolutionary stages, especially during the 8th to 10 th week of infection. In the granulomas fusiform cells with prominent endoplasmic reticulum were frequen'tly seen together with macrophages, lymphocytes and eosinophils within a matrix containing variable amount of collagen fibrils. At the 10 th week after infection periovular granulomas presented variable degrees of fibrosis, especially at their periphery. FSC did not appear within granulomas observed by electron microscopy, although this cell type could be observed in its normal perisinusoidal location presenting fat va- cuoles with a diameter up to $3 \mu \mathrm{m}$. By light microscopy, the FSC could be identified only in epon-sections.

Outside of the granulomas the liver presented focal areas of coagulative necrosis, increase in size and number of sinusoidal cells and dense eosinophilic and lymphocytic infiltration in the portal spaces and around central veins.

\section{Non-infected, vitamin A treated animals}

Treatment with vitamin A alone did not alter the parenchymal cells of the liver, and did not induce inflammation or fibrosis, but caused the FSC to appear with large fat droplets having a diameter up to $9 \mu \mathrm{m}$ and occupying most of the cytoplasm (Fig. 1). These enlarged vacuolated cells were easily spotted by light microscopy in routine stained paraffin sections. Identification was even better in epon-embedded sections stained with toluidineblue and examined with high-resolution light microscopy. Only occasionally was a similarly vacuolated cell also detected in the portal connective tissue. These alterations were present at all time intervals investigated, and had not progressed at later intervals.

\section{Infected, vitamin A-treated animals}

In the infected animals treated with vitamin A, vacuolated cells similar in appearance to those in the non-infected vitamin A-treated animals were seen by light microscopy at the perisinusoidal area of the liver tissue not involved in the formation of granulomas (Fig. 2) and within periovular granulomas (Fig. 3).

Under the electron microscope no fundamental difference was noted in the granulomas compared with

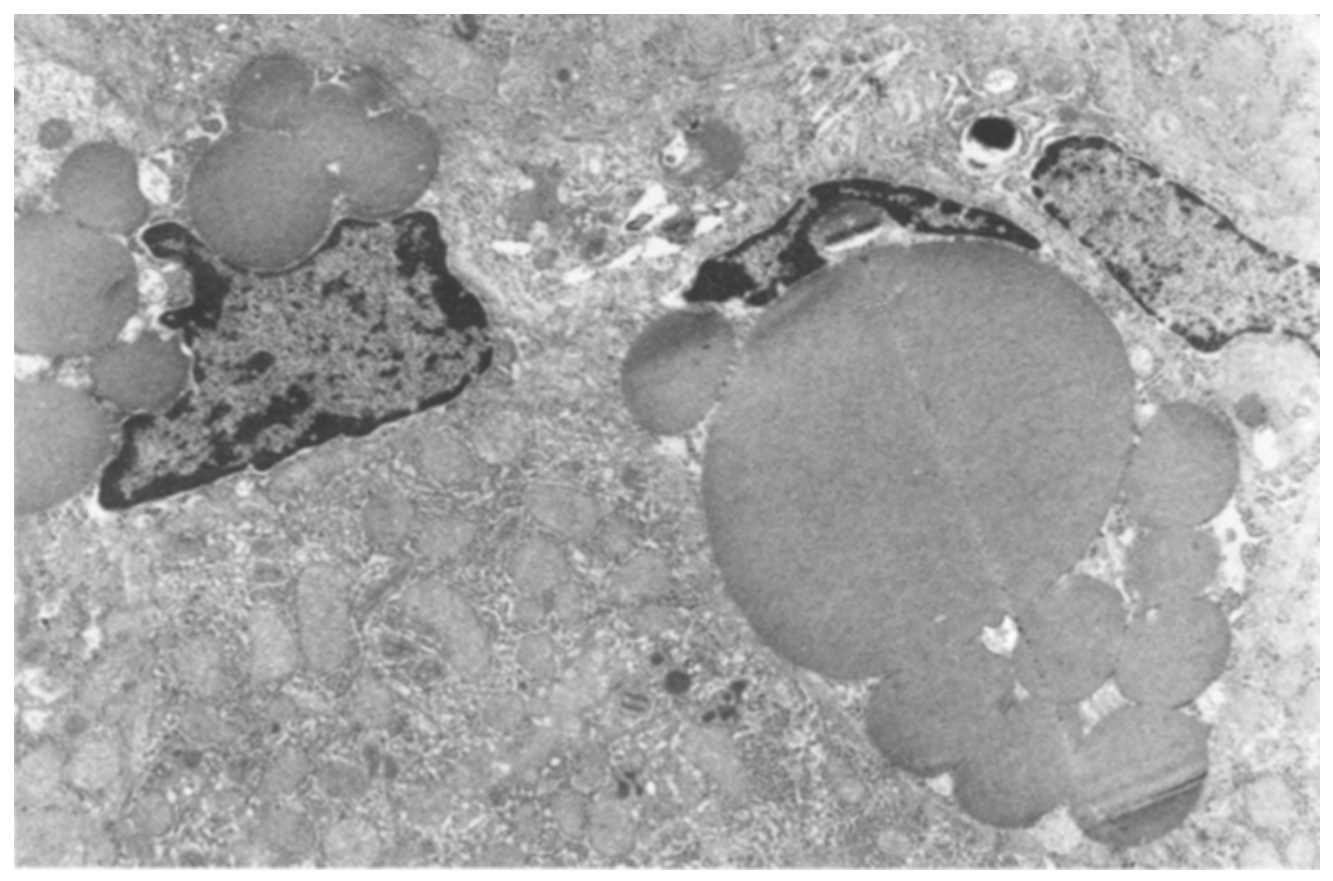

Fig. 1. Normal mouse treated with vitamin A. Two enlarged fat-storing cells appear in the sinusoids. Electron microscopy, $\times 10000$ 


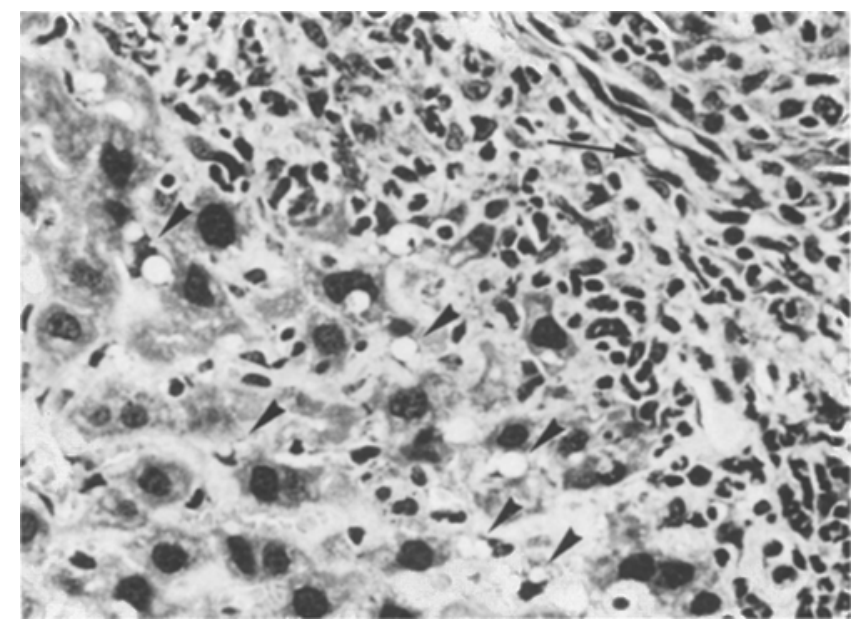

Fig. 2. Cells with empty vacuoles (FSC) can be seen in the sinusoids (arrowheads) and inside the granulomatous inflammatory area (arrow) in the liver of a mouse infected with $S$. mansoni and treated with vitamin $\mathrm{A}$. $\mathrm{HE}, \times 400$

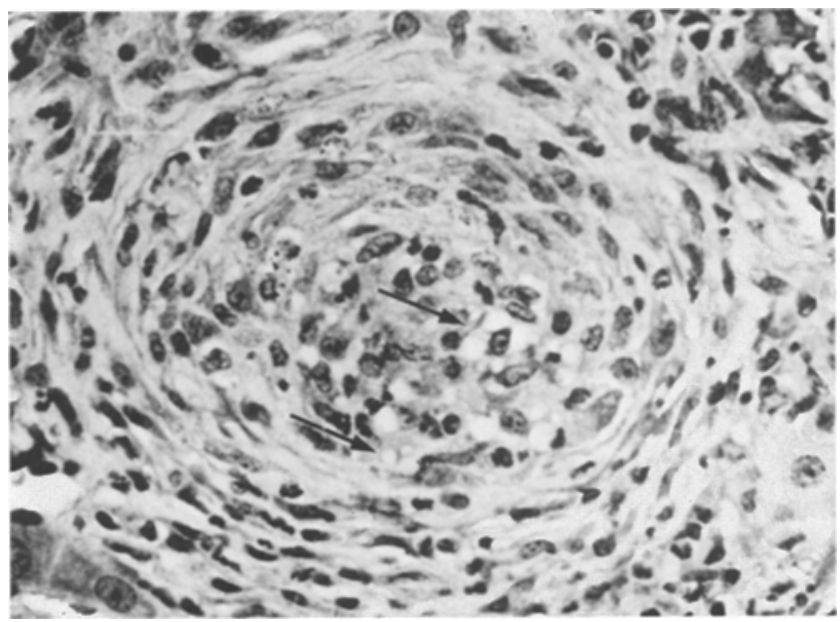

Fig. 3. A mature schistosomal granuloma in the liver of a mouse treated with vitamin A. Vacuolated cells (FSC) can be identified among the granulomatous cells (arrows). HE, $\times 400$

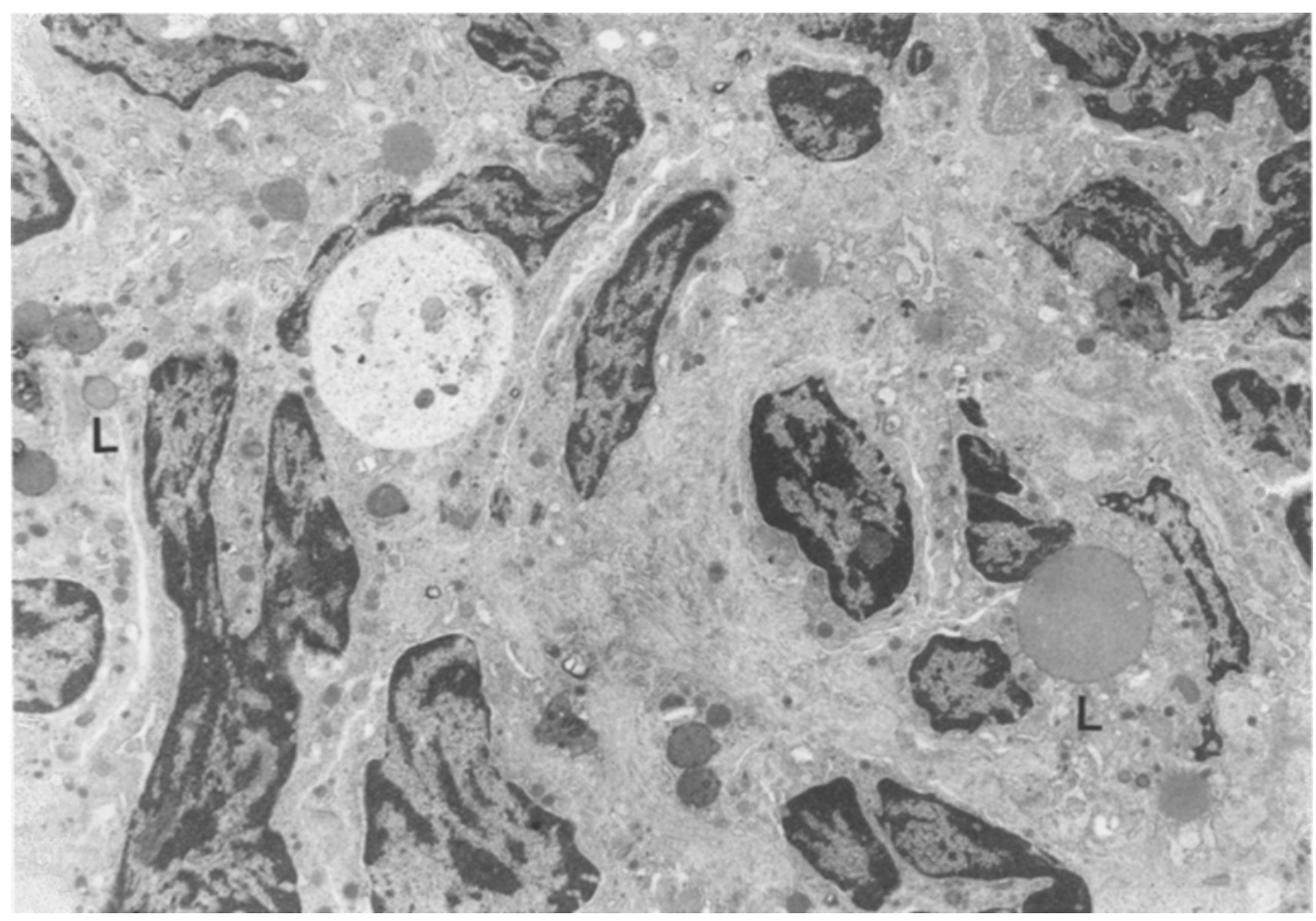

Fig. 4. Schistosomal periovular granuloma in the liver of a vitamin A-treated mouse. Large and small lipid droplets $(L)$ can be seen in the cytoplasm of cells involved in the inflammatory reaction. These are probably FSC in the process of differentiating into fibroblast-like cells. Electron microscopy, $\times 10000$ those in infected controls, except for the fact that the fusiform cells in the granulomas showed large fat droplets of variable size and electron density. Many of them were very small, appearing as tiny dark dots within the cell cytoplasm (Fig. 4). Apparently, FSC progressively lost their cytoplasmic fat droplets while increasing the amount of endoplasmic reticulum when they were present in more mature granulomas, but cytoplasmic fat droplets were seen even during the fibrotic stage. Fusiform, fibroblast-like cells with lipid droplets in the cytoplasm were observed, surrounded by collagen fibrils at the granuloma periphery (Fig. 5).
Thin and long fibrous septa were occasionally formed near the granulomas. These septa radiated into the liver parenchyma sometimes connecting portal spaces to central canals. Under the electron microscope these tracts were bordered by liver cell cords and/or sinusoidal walls on both sides. They were formed by a collagen-rich matrix containing prominent fat-storing fibroblast-like and/ or myofibroblast-like cells (Fig. 6).

The overall picture of reactive hepatitis (isolated liver cell necrosis, focal, periportal and pericentral lymphocytic infiltrations, and hypertrophy of sinusoidal cells) was more severe in vitamin A-treated than in non-treated, infected mice. 

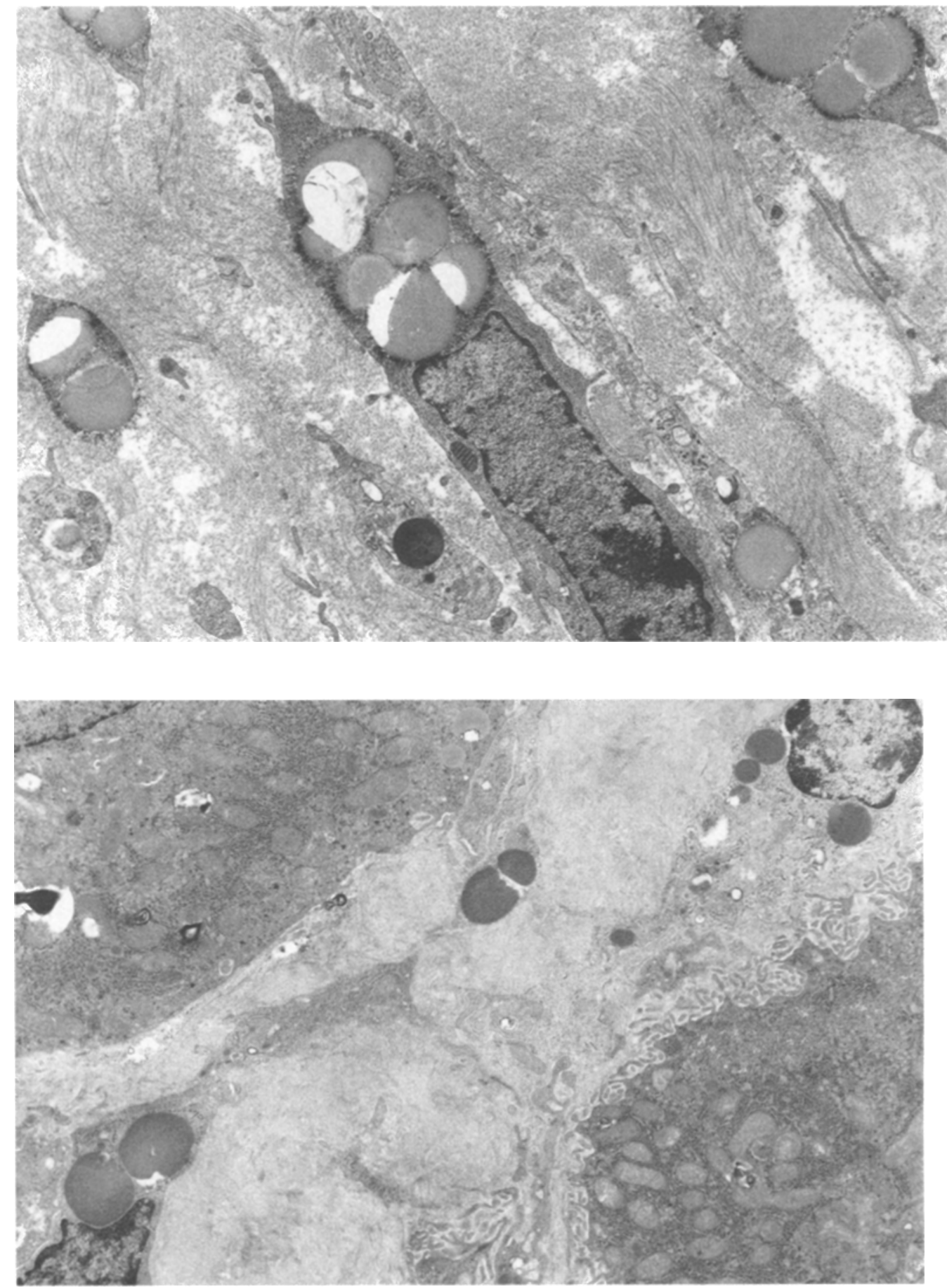

Fig. 5. Zone of fibrosis at the periphery of a schistosomal granuloma in the mouse liver. The animal has been treated with vita$\min$ A. Fusiform fat-storing cells are present in the middle of abundant collagen fibrils. Electron microscopy, $\times 10000$
Fig. 6. Septal fibrosis of the liver in a vitamin A treated, $S$. mansoni-infected mouse. Fat-storing cells are present within this rich collagenous matrix. Electron microscopy, $\times 10000$

\section{Discussion}

The present investigation provides evidence that perisinusoidal cells containing large fat cytoplasmic droplets as a result of previous vitamin A treatment become concentrated within focal areas of schistosomal granuloma formation in the liver of mice.

The precise mechanism underlying the accumulation of the FSC within periportal granulomas remains to be defined. There are no data in the literature to show that FSC can actively "migrate" into a field of focal lesion. One possible explanation could be in situ proliferation of such cells. Proliferation of FSC in vitro has been demonstrated in several studies (for review see Ramadori 1991). On the other hand, vitamin A is known to have a cellular anti-proliferative effect (Sacks et al. 1992). Another possibility is that myofibroblasts present in the granulomas could undergo a phenotypic transformation into fat-storing cells under the load of vitamin A administration, as has been demonstrated in vitro (Borojevic et al. 1991).

Observations concerning the participation of FSC in the schistosomal granuloma serve to re-emphasize the importance of such cells in hepatic fibrogenesis, even 
when it occurs outside the sinusoidal territory. Concentration of FSC around a focal hepatic lesion had already been observed when an intraparenchymal lesion was inflicted by thrusting a liquid nitrogen-cooled or a fireheated needle into the liver (Ogawa et al. 1985), or when tiny intraparenchymal granulomas were produced by the injection of particulate pig alkaline phosphatase into rats (Dijkhuis et al. 1989). The schistosomal granuloma is another type of focal lesion. It is a periportal, fibrogenic, cell-mediated hypersensitive reaction induced by a parasite egg (Phillips and Colley 1978).

Within areas of dense fibrosis, fusiform cells containing cytoplasmic fat droplets were seen. This finding suggests that FSC from vitamin A-treated animals can differentiate and be engaged in active fibrogenesis while still maintaining cytoplasmic fat droplets. This is in discrepancy with some data from the literature. Previous treatment with vitamin A was shown to prevent the development of post-necrotic fibrosis after carbon tetrachloride intoxication or of septal fibrosis that follows repeated pig-serum administration to rats (Mobley et al. 1991 ; Senoo and Wake 1985). Glycosylation, an important step for the synthetic-secretory cell activity, is depressed in acute and chronic hypervitaminosis A (Martiu and Morré 1988). However, excess vitamin A administration did not prevent schistosomal granuloma fibrosis in the present experimental conditions. Such discrepancies might be due to differences in doses and schedules of vitamin $\mathrm{A}$ administration, in animal strains, and in the fibrogenic stimuli. Also, modulation of FSC functions appears to be complex both in vitro and in vivo. Retinoic acid can differentially modulate several key features of hepatic fibrogenesis (Davis et al. 1990). Response to cytokines, especially to TGF-B, by FSC may depend on the nature of the matrix components present, such as various collagen types (Davis and Vucic 1989). It seems that accumulation of excess vitamin A in FSC fat droplets depresses the ability of the FSC to be activated and to differentiate, but the degree of such effects may be variable. The activated cell tends to diminish gradually the number and size of fat droplets but some droplets still remain in vitamin A-treated animals for long enough to allow identification of FSC in pathological processes.

No evidence of parenchymal cell injury were seen in the vitamin A-treated control mice. However, eight infected and vitamin A-treated animals died during treatment and the changes of reactive hepatitis, which are associated with early schistosomal infection, were apparently enhanced. Such an enhancing effect of vitamin A is known also from experimental liver injury induced by endotoxin (Earnest et al. 1986) or by ethanol (Lieber and Leo 1986).

FSC play an important role in the pathogenesis of septal fibrosis of the liver (Andrade 1991). Septal fibrosis is a non-specific feature of several chronic liver diseases of man and can become prominent in some of them, such as in incomplete septal cirrhosis (Sciot et al. 1988), chronic septal hepatitis (Gerber and Vernace 1974) and schistosomiasis (Andrade 1989). Our present findings confirm that many activated fat-storing connective tissue cells are present in septal hepatic fibrosis associated with experimental schistosomiasis.

\section{References}

Andrade ZA (1989) Evolution and involution of hepatosplenic schistosomiasis. Mem Inst Oswaldo Cruz 84 [Suppl 1]:58-75

Andrade ZA (1991) Contribution to the study of septal fibrosis of the liver. Int J Exp Pathol 72:553-562

Borojevic R, Guaragna RM, Margis R, Margis MP, Vicente CP, Silva LC (1991) In vitro conversion of a hepatic myofibroblast cell line GRX into lipocytes (Ito cells). In: Wisse E, Knook DL, McCuskey RS (eds) Cells of the hepatic sinusoid, vol 3. The Kupffer Cell Foundation, Rijswijk, pp 249-252

Davis BH, Vucic A (1989) Modulation of vitamin A metabolism during hepatic and intestinal cell culture. Biochim Biophys Acta 1010:318-324

Davis BH, Kramer RT, Davidson NO (1990) Retinoic acid modulates rat Ito cell proliferation, collagen and transforming growth factor B production. J Clin Invest 86:2062-2070

Dijkhuis FWJ, Jonker AM, Koudstaal J, Hardonk MJ (1989) Involvement of perisinusoidal fat-storing cells in the development of granulomatous structures in the rat liver. In: Wisse E, Knook DI, Decker K (eds) Cells of the hepatic sinusoid, vol 2. Kupffer Cell Foundation, Rijswijk, pp 76-79

Earnest DL, Brower A, Sim WW, Horan MA, Hendricks HFJ, De Leeuw AM, Knook DL (1986) Hypervitaminosis A activates Kupffer cells and lowers the threshold for endotoxin liver injury. In: Kirn A, Knook DL, Wisse E (eds) Cells of the hepatic sinusoid, vol 1. The Kupffer Cell Foundation, Rijswijk, pp 277-282

Friedman SL, Roll FJ, Boyles J, Bissel DM (1985) Hepatic lipocytes: the principal collagen-producing cells of normal rat liver. Proc Natl Acad Sci 82:8681-8685

Gerber MA, Vernace S (1974) Chronic septal hepatitis. Virchow's Arch [A] 362:303-309

Gressner AM, Bachem MG (1990) Cellular sources of noncollagenous matrix proteins: role of fat-storing cells in fibrogenesis. Semin Liver Dis 10:30-46

Gressner AM, Haarmann R (1989) Hyaluronic acid synthesis and secretion by rat liver fat-storing cells (perisinusoidal lipocytes) in culture. Biochem Biophys Res Commun 151:222-229

Koizumi T, Nakamura N (1985) Glycosaminoglycans in hepatic fibrosis. In: Hirayama C, Kivirikko KI (eds) Pathobiology of hepatic fibrosis. Elsevier Science Publishers (Biomedical Division), New York, pp 57-63

Lieber CS, Leo MA (1986) Interaction of alcohol and nutritional factors with hepatic fibrosis. In: Popper H, Schaffner F (eds) Progress in liver diseases, vol VIII. Grune \& Stratton, New York, pp 253-272

Maher JJ, Friedman SL, Roll FJ, Bissel DM (1988) Immunolocalization of laminin in normal rat liver and biosynthesis of laminin by hepatic lipocytes in primary culture. Gastroenterology 94:1053-1062

Martiu BR, Morré DM (1988) Excess vitamin A decreases the specific activity of galactosyltransferase in Golgi apparatus of rat liver. J Nutr 118:968-975

McGee JO'D, Patrick RS (1972) The role of perisinusoidal cells in hepatic fibrogenesis. An electron microscope study of acute carbon tetrachloride liver injury. Lab Invest 26:429-440

Mobley SA, Earnest DE, Sim WW, McCuskey PA, McCuskey RA, Sipes IG (1991) Retinol administration decreases collagen deposition in rats given repeated doses of carbon tetrachloride. In: Wisse E, Knook DL, McCuskey RS (eds) Cells of the hepatic sinusoid, vol 3. The Kupffer Cell Foundation, Rijswijk, pp 188-191

Ogawa K, Suzuki JI, Narasaki M, Mori M (1985) Healing of focal injury in rat liver. Am J Pathol 119:158-167 
Phillips SM, Colley DG (1978) Immunologic aspects of host responses to schistosomiasis: resistance, immunopathology and eosinophil involvement. Prog Allergy 24:49-182

Ramadori G (1991) The stellate cell (Ito-cell, fat-storing cell, lipocyte, perisinusoidal cell) of the liver. New insights into pathophysiology of an intriguing cell. Virchow's Arch [B] 61:147-158

Ramadori G, Rieder H, Knittel TP, Dienes HP, Meyer von Buschenfelde KH (1987) Fat storing cells (FSC) of rat liver synthesize and secrete fibronectin. J Hepatol 4:190-197

Sacks PG, Oke V, Mehta K (1992) Antiproliferative effects of free and liposome-encapsulated retinoic acid in a squamous carcinoma model: monolayer cells and multicellular tumor spheroids. J Cancer Res Clin Oncol 118:490-496
Schafer S, Zerbo O, Gressner AM (1987) The synthesis of proteoglycans in fat-storing cells of rat liver. Hepatology 7:680-687

Sciot R, Staessen D, Van Damme B, Van Steenbergen W, Fevery J, de Groote J, Desmet VJ (1988) Incomplete septal cirrhosis: histopathological aspects. Histopathology 13:593-603

Senoo H, Wake K (1985) Suppression of experimental hepatic fibrosis by administration of vitamin A. Lab Invest 52:182-194

Senoo H, Hata R, Nagai Y, Wake K (1984) Stellate cells (vitamin A storing cells) are the primary site of collagen synthesis in nonparenchymal cells in the liver. Biomed Res $5: 451-458$

Stenger RJ (1966) Hepatic sinusoids in carbon tetrachloride-induced cirrhosis. An electron microscopic study. Arch Pathol $81: 439-447$ 